\section{Digital Image Analysis of Sweetpotato Storage Roots in Herbicide Trials}

\author{
Arthur Villordon ${ }^{1}$ and Heather Carroll ${ }^{2}$ \\ Louisiana State University Agricultural Center, Louisiana Agricultural \\ Experiment Station, Sweet Potato Research Station, P.O. Box 120, Chase, \\ LA 71324-0120
}

Additional index words. Ipomoea batatas

\begin{abstract}
Digital image analysis (DIA) was evaluated for use in assessing size and shape attributes of sweetpotato [Ipomoea batatas (L.) Lam.] storage roots in herbicide studies. Digital image files of U.S. no. 1 storage roots were taken using a digital camera. Image analysis was performed using a publicly available software package. Eight size and shape attributes were measured and subjected to univariate and multivariate procedures. DIA revealed differences for storage root width and roundness attributes. Principal component analysis suggested that storage root length, width, and roundness best described the variability of the storage root sample. The results demonstrate the potential use of DIA in augmenting data from sweetpotato herbicide trials as well as other investigations that require information about storage root size and shape responses.
\end{abstract}

Previous sweetpotato herbicide studies evaluated treatment effects on crop vigor and yield, but limited information was gathered about storage root morphological responses (Harrison and Dukes, 1996; Harrison et al., 1985; Motsenbocker and Monaco, 1993). Currently, there is no known published method that routinely assesses sweetpotato storage root size and shape attributes. Such a method will potentially detect possible herbicide effects on storage roots that are not measurable using current visually based procedures or grading methods.

Digital image analysis (DIA) has become an important tool in the quantification of plant characters, especially those that require tedious measurements. In particular, DIA has been routinely used to measure plant root attributes like length, diameter, width, and area (Iwata et al., 1998; Lebowitz, 1988; Tagliavini et al., 1993). This study evaluates the feasibility of digitally assessing size and shape attributes in sweetpotato storage roots, in particular those obtained from herbicide studies.

U.S. no. 1 (5.1-8.9 cm diameter, 7.6-22.9 $\mathrm{cm}$ long) 'Beauregard' sweetpotato storage root samples were obtained from the 2000 herbicide study at the Sweet Potato Research Station in Chase, La. The treatments are summarized in Table 1. Sample number ranged from 15 to 30 per treatment for a total of 420 . A grading board was used to ensure that the specifications for the U.S. no. 1 grade were strictly met. Digital images (jpeg format) of

Received for publication 11 May 2001. Accepted for publication 20 Nov. 2001. Approved for publication by the director of the Louisiana Agricultural Experiment Station as manuscript no. 01-90-0294. Mention of trade or company names does not imply endorsement by the Louisiana State Univ. Agricultural Center nor criticism of similar products not named.

${ }^{1}$ Assisant Professor. E-mail address: avillordon@ agctr.lsu.edu

${ }^{2}$ Research Associate.
Thresholding was considered optimum when pixel allocation unambiguously differentiated sample objects from a dark background. The object analysis phase measured eight attributes or variables (Table 2). AREA, PERIM, MAXIS, and FDIA were square root-transformed prior to analysis to satisfy normality assumptions. Data were separately analyzed using both univariate and multivariate procedures. First, ANOVAs were performed for each variable using SAS PROC GLM (SAS Institute, Cary, N.C.). Subsequently, principal component analysis (PCA) was performed using SAS PROC PRINCOMP (correlation matrix) to identify: 1) the number of principal components using the cumulative proportion of total variance, and 2) a subset of variables that best described variability in the data set.

Although the storage root sample was strictly graded, DIA revealed significant differences for $\operatorname{MINAX}(P=0.03$, Table 1$)$, a size attribute, and ROUND $(P=0.05$, Table 1$)$, a shape attribute that is pose (location, orientation, and size) invariant (Glasbey and Horgan, 1995). Even though the current study does not identify the specific cause of these observed differences, DIA can be used in future studies to assist in the identification of the specific cause of size and shape differences. Using the multivariate data analysis approach, PCA revealed that the first three principal components accounted for $97 \%$ of the total observed variability. From a multivariate analysis point of view, MAXIS, MINAX, and ROUND will best describe size and shape variation of the storage root sample based on the examination of the eigenvector elements (Khattree and Naik, 2000). images, manual thresholding, calibration, object identification, and object analysis.

storage roots against a black background were taken using a light stand-mounted Olympus D-360 L camera (Olympus, Tokyo) at a reso$640 \times 480$ pixels. Five to eight was included in all images to facilitate calib files were imported into Im Version 2 (Univ. of Texas Health Science Center at San Antonio, available from ftp:// maxrad6.uthscsa.edu) and processed using the following steps: conversion into grayscale

Table 1. Effects of various weed control treatments on selected sweetpotato storage root digital image attributes as measured by Image Tool. ${ }^{\mathrm{z}}$

\begin{tabular}{|c|c|c|c|c|}
\hline \multirow[b]{2}{*}{ Herbicide } & & \multirow{2}{*}{$\begin{array}{l}\text { Application } \\
\text { rate } \\
\left(\mathrm{kg} \cdot \mathrm{ha}^{-1} \text { a.i. }\right)\end{array}$} & \multicolumn{2}{|c|}{ Attribute $^{y}$} \\
\hline & & & \multicolumn{2}{|c|}{$\overline{\text { MINAX ROUND }}$} \\
\hline Fomesafen & Reflex 2LC, Zeneca, Richmond, CA & 0.55 & 5.961 & 0.295 \\
\hline Thiazopyr & Visor 2E, Rohm and Haas, Philadelphia, PA & 0.27 & 5.920 & 0.265 \\
\hline Hand-weeded & & & 5.790 & 0.285 \\
\hline Metolachlor & Dual Magnum, Novartis, Greensboro, NC & 1.12 & 5.748 & 0.359 \\
\hline Metribuzin & & & & \\
\hline $\begin{array}{l}+ \text { Clomazone } \\
\text { EPTC }\end{array}$ & Sencor DF, Bayer + Command 3ME, FMC & $1.12+1.16$ & 5.719 & 0.287 \\
\hline + Clomazone & Eptam 7E, Zeneca + Command 3ME, FMC & $3.34+0.58$ & 5.659 & 0.299 \\
\hline Metolachlor & Dual Magnum, Novartis, Greensboro, NC & 2.24 & 5.633 & 0.308 \\
\hline Dimethenamid & Frontier 6, BASF, Research Triangle, NC & 1.32 & 5.503 & 0.272 \\
\hline Thiazopyr & Visor 2E, Rohm and Haas, Philadelphia, PA & 0.55 & 5.493 & 0.295 \\
\hline Dimethenamid & Frontier 6, BASF, Research Triangle, NC & 0.66 & 5.478 & 0.284 \\
\hline Metribuzin & & & & \\
\hline + Clomazone & Sencor DF, Bayer + Command 3ME, FMC & $1.12+0.56$ & 5.423 & 0.324 \\
\hline EPTC & Eptam 7E, Zeneca, Richmond, CA & 3.34 & 5.397 & 0.279 \\
\hline Fomesafen & Reflex 2LC, Zeneca, Richmond, CA & 0.27 & 5.381 & 0.283 \\
\hline EPTC & & & & \\
\hline + Clomazone & Eptam 7E, Zeneca + Command 3ME, FMC & $3.34+1.16$ & 5.353 & 0.327 \\
\hline Clomazone & Command 3ME, FMC, Philadelphia, PA & 0.58 & 5.312 & 0.322 \\
\hline Not weeded & & & 5.312 & 0.288 \\
\hline EPTC & Eptam 7E, Zeneca, Richmond, CA & 6.68 & 5.290 & 0.287 \\
\hline$P$ value & & & 0.03 & 0.05 \\
\hline $\mathrm{LSD}_{0.05}$ & & & 0.468 & 0.051 \\
\hline $\mathrm{CV}(\%)$ & & & 14.78 & 30.28 \\
\hline
\end{tabular}

${ }^{2}$ UTHSCSA Image Tool program Version 2 (developed at the Univ. of Texas Health Science Center at San Antonio, Texas, and available from the Internet by anonymous FTP from ftp://maxrad6.uthscsa.edu). ${ }^{y}$ MINAX $=$ the length of the longest line that can be drawn through the object perpendicular to the major axis. ROUND $=(4 \times \mathrm{PI} \times$ area $) /$ perimenter. $1=$ object is more round. 
Table 2. Description of object attributes that were measured by Image Tool. ${ }^{2}$

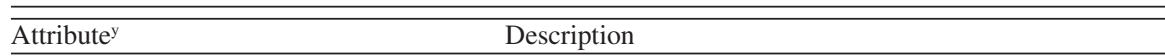

Area

(AREA)

Perimeter

(PERIM)

Roundness

(ROUND)

Elongation

(ELONG)

Feret diameter (FDIAM)

Compactness

(COMPA)

Major axis length The length of the longest line that can be drawn through the object.

(MAXIS)

Minor axis length The length of the longest line that can be drawn through the object perpendicular (MINAX) to MAXIS.

${ }^{2}$ UTHSCSA Image Tool program Version 2 (developed at the Univ. of Texas Health Science Center at San Antonio, Texas, and available from the Internet by anonymous FTP from ftp://maxrad6.uthscsa.edu).

Description of the object attributes obtained from accompanying software documentation.

${ }^{y}$ All measurement units in unit of calibration, i.e., cm. PI =3.1416.
The results illustrate the potential for DIA to enhance information from herbicide studies as well as other investigations that require data about sweetpotato storage root size and shape responses. For example, DIA can be used as a tool to quantify storage root shape for breeding purposes. To assess its robustness, it is necessary to further evaluate this procedure under various experimental conditions and growing environments.

\section{Literature Cited}

Glasbey, C.A. and G.W.Horgan. 1995. Image analysis for the biological sciences. Wiley, New York.

Harrison, H.F., Jr., and P.D. Dukes. 1996. Sensitivity of four sweetpotato clones to metribuzin herbicide. HortScience 31:846-847.

Harrison, H.F. Jr., A. Jones, and P.D. Dukes. 1985. Differential response of six sweet potato (Ipomoea batatas) cultivars to metribuzin. Weed Sci. 33:730-733.

Iwata, H., S. Niikura, S. Matsuura, Y. Takano, and Y. Ukai. 1998. Evaluation of variation of root shape of Japanese radish (Raphanus sativus L.) based on image analysis using elliptic Fourier descriptors. Euphytica 102:143-149.

Khattree, R. and D.N. Naik. 2000. Multivariate data reduction and discrimination with SAS software. SAS Inst., Cary, N.C.

Lebowitz, R.J. 1988. Digital image analysis measurement of root length and diameter. Environ. Expt. Bot. 28:267-273.

Motsenbocker, C.E. and T.J. Monaco. 1993. Differential tolerance of sweet potato (Ipomoed batatas) clones to metribuzin. Weed Tech. 7:349-354.

Tagliavini, M., L.J. Veto, and N.E. Looney. 1993. Measuring root surface area and mean root diameter of peach seedlings by digital image analysis. HortScience 28:1129-1130. 